numbers she produced. I suggest a long drink of cold water.

It seems to me to be a great pity that we should all be agreeing meekly with the politician's diktat that if resources are to be improved in the periphery then this can only be done by allowing services to deteriorate at the centre: we are heading for an NHS that is uniformly under-resourced, with satisfactory conditions only for those in the private sector (who may indeed be middle class, and have relatively minor illnesses). If we dissipate our energy in attacking one another, and no one stands up for a better NHS with adequate resources at both teaching hospital and peripheral unit, we shall have no one to blame but ourselves. And that really would be shameful.

University Hospital of South Manchester West Didsbury, Manchester

REFERENCE

IGoldberg. D. (1985) Implementation of Mental Health Services in North West England. Paper presented at the Royal College of Psychiatrists/DHSS Conference on Mental Health Service Planning held in March 1985. Publication of proceedings in preparation.

[This correspondence is now closed-Eds.]

\section{Experience of a community-based approach to alcoholism}

\section{DeAR SIRS}

Intoxication is a maladaptive coping mechanism which disrupts family life, produces a familiar toll of deaths from ill health, injuries on the roads in accidents, in assaults and vandalism and in suicides. For the less disturbed psychiatry will offer re-education in coping strategies which can offer an alternative to intoxication by drink or drugs.

There is difficulty in dealing with these re-educative areas in the Health Service as the most effective treatments involve psychotherapeutic techniques often over long periods of time. Patients with drink and drug problems often need the help of long-term support groups. Relapse may also be frequent and disheartening for both patients and therapists.

The cost of providing manpower for such treatments offered by statutory health authorities is potentially far greater than the cost of the machinery for high technology medicine. Despite the identification of psychiatric services as priority areas for health expenditure, it remains a Cinderella specialty when funds are distributed. Despite the conflict between rising costs and rising expectations for quality of health care there is a popular and therefore political demand to improve these psychiatric services.

One solution is for the NHS to work in close collaboration with voluntary agencies. An example in the field of addiction treatment and prevention is ACCEPT-an acronym derived from Alcoholism Community Centres for Education, Prevention and Treatment. ACCEPT is a charity which operates day centre treatment facilities offering a wide variety of sophisticated psychotherapeutic techniques which would be envied by most psychiatric day hospitals. As part of my higher professional training at St George's Hospital Medical School I have been able to spend time working at ACCEPT's major centre in Fulham, which deals with upwards of 100 new cases per month.

This has been a fascinating experience with several benefits. I have had access to the clients there and have therefore been able to see a much greater range of presentations of addiction problems than that afforded by the patients referred to psychiatric services or even presenting in general practice. I have also learned how to work with the lay and voluntary workers and allow them to make use of my skills and obtain psychiatric advice for their clients. I have conducted group and individual therapy and been able to offer this to people who could not have been prepared to participate in such treatment under a label of psychiatric treatment, but who found attendance at a community agency fully acceptable.

The quality of intervention and its continuity of therapists over time is remarkable and better or equal to that of the best neurosis units in the health service whose numbers are, of course, very limited because of their high costs. I have also been able to gather research data from the client group to further my own interest in addiction problems.

I have found my experience very worthwhile and suggest it would be a useful model for the future. It shows that both training and service functions can be provided by voluntary agencies in co-operation with the NHS and that they complement each other and achieve good results as well as significant financial savings. The experience also brings community involvement in psychiatric care to life with the committed involvement of both sides which is essential for any real success.

St George's Hosptial

ROBERT HiLl

London SWI7

\section{Education in health care of people with mental handicap}

\section{DeAr SirS}

In the past most doctors have often received little undergraduate or postgraduate teaching about mental handicap. That they have often been at a loss to help mentally handicapped people has been noticed by the parents of mentally handicapped children. Specialists in Developmental Paediatrics and Child Health have seen an increasing proportion of, but never all, mentally handicapped children. General Medical Specialists treat mentally handicapped people referred to them with particular complaints, but they are not concerned with these patients' lives as a whole.

A need for more teaching of doctors about mental handicap is emerging so that family doctors can help the mentally handicapped more confidently. Continuing specialist help is also required for a variety of problems. Teaching on mental handicap has tended to become a catalogue of relatively rare conditions, but today there is an opportunity to develop teaching more widely as the 'health care of people with mental handicap'. 